\title{
Why is malaria associated with poverty? Findings from a cohort study in rural Uganda
}

Lucy S. Tusting ${ }^{1,2^{*}}$, John Rek ${ }^{3}$, Emmanuel Arinaitwe ${ }^{3,4}$, Sarah G. Staedke ${ }^{3,4}$, Moses R. Kamya ${ }^{5}$, Jorge Cano ${ }^{1}$, Christian Bottomley ${ }^{6}$, Deborah Johnston ${ }^{7}$, Grant Dorsey ${ }^{8}$, Steve W. Lindsay ${ }^{9}$ and Jo Lines ${ }^{1}$

\begin{abstract}
Background: Malaria control and sustainable development are linked, but implementation of 'multisectoral' intervention is restricted by a limited understanding of the causal pathways between poverty and malaria. We investigated the relationships between socioeconomic position (SEP), potential determinants of SEP, and malaria in Nagongera, rural Uganda.

Methods: Socioeconomic information was collected for 318 children aged six months to 10 years living in 100 households, who were followed for up to 36 months. Mosquito density was recorded using monthly light trap collections. Parasite prevalence was measured routinely every three months and malaria incidence determined by passive case detection. First, we evaluated the association between success in smallholder agriculture (the primary livelihood source) and SEP. Second, we explored socioeconomic risk factors for human biting rate $(\mathrm{HBR})$, parasite prevalence and incidence of clinical malaria, and spatial clustering of socioeconomic variables. Third, we investigated the role of selected factors in mediating the association between SEP and malaria.

Results: Relative agricultural success was associated with higher SEP. In turn, high SEP was associated with lower HBR (highest versus lowest wealth index tertile: Incidence Rate Ratio $0.71,95 \%$ confidence intervals (CI) $0.54-0.93, P=0.01$ ) and lower odds of malaria infection in children (highest versus lowest wealth index tertile: adjusted Odds Ratio 0.52 , $95 \% \mathrm{Cl} 0.35-0.78, P=0.001$ ), but SEP was not associated with clinical malaria incidence. Mediation analysis suggested that part of the total effect of SEP on malaria infection risk was explained by house type (24.9\%, $95 \%$ Cl 15.8-58.6 \%) and food security (18.6\%, $95 \%$ Cl 11.6-48.3\%); however, the assumptions of the mediation analysis may not have been fully met.
\end{abstract}

Conclusion: Housing improvements and agricultural development interventions to reduce poverty merit further investigation as multisectoral interventions against malaria. Further interdisplinary research is needed to understand fully the complex pathways between poverty and malaria and to develop strategies for sustainable malaria control.

Keywords: Malaria, Socioeconomic, Poverty, Development, Housing, Wealth index, Uganda

\footnotetext{
* Correspondence: lucy.tusting@lshtm.ac.uk

${ }^{1}$ Department of Disease Control, London School of Hygiene \& Tropical

Medicine, London, UK

${ }^{2}$ Big Data Institute, Nuffield Department of Medicine, University of Oxford,

Oxford, UK

Full list of author information is available at the end of the article
} 


\section{Multilingual abstracts}

Please see Additional file 1 for translations of the abstract into the six official working languages of the United Nations.

\section{Background}

As attention shifts to the Sustainable Development Goals, malaria control is at a pivotal juncture. The past 15 years have seen a $37 \%$ fall in annual global incidence [1], largely driven by the scale-up of long-lasting insecticide-treated nets (LLINs), indoor residual spraying and improved case management [2]. While these are highly effective interventions, malaria is closely associated with poverty and underdevelopment. Therefore, in the long-term, there is arguably a need for more sustainable control strategies that embrace non-health sectors, including agriculture, water and sanitation, and housing [3]. Historically, social and environmental changes contributed to malaria elimination in the USA and Europe [4]. Reflecting this, the 2013 Multisectoral Action Framework for Malaria outlined practical steps to target the social and environmental determinants of malaria [5]. More recently the World Health Organization's 2015 Global Technical Strategy for Malaria and the complementary Roll Back Malaria action plan both seek to link malaria control with sustainable development [6].

Yet despite the potential value of a multisectoral approach to malaria, our understanding of how to target such intervention remains poor [5]. Research on socioeconomic risk factors for malaria has proliferated in the past decade and studies in a range of African settings have observed that the odds of malaria infection are on average doubled in children with the lowest socioeconomic position (SEP) (as measured by household wealth index scores or parents' educational status or occupation), compared with children with the highest SEP within the same community [3]. However, to our knowledge, no published studies have explicitly explored the underlying causal pathways between household-level poverty and malaria. While there is evidence of reverse causality from malaria to poverty $[7,8]$, wealth in turn can help to protect against malaria. This protection may stem from better access to health care, LLIN coverage, treatment-seeking behaviour, housing quality and food security among other variables [9-11], yet the relative contribution of these factors remains unknown. Furthermore, few malaria studies have considered the determinants of rural poverty itself, limiting the evidence on the potential overlap between development initiatives and malaria control [5]. Here we aim to narrow these knowledge gaps through a novel, interdisciplinary investigation of the association between SEP, its determinants, and malaria among children in Nagongera, Uganda, a rural area with high malaria transmission. To our knowledge, the present study is the first explicitly to investigate factors mediating the relationship between SEP and malaria.

\section{Methods \\ Study site}

The study was carried out between August 2011 and September 2014 in Nagongera sub-country, Tororo, Uganda $\left(00^{\circ} 46^{\prime} 10.6^{\prime \prime} \mathrm{N}, 34^{\circ} 01^{\prime} 34.1^{\prime \prime} \mathrm{E}\right)$. Malaria transmission is intense with two annual peaks following the two rainy seasons (March to May and August to October). During 2011-2013 the estimated annual Plasmodium falciparum entomological inoculation rate was 125 [12] and malaria incidence in children was 2.8 episodes per person year at risk [13]. $36 \%$ of households have at least one LLIN per two residents but IRS is not currently done [13]. Smallholder agriculture is the primary livelihood source. Average gross national income per capita in Uganda in 2014 was US\$ 670 (current prices) [14].

\section{Cohort study}

This study was part of a cohort study, described elsewhere, which was designed to compare temporal changes in malaria incidence from the cohort with temporal changes in malaria test positivity rate from health facility based surveillance $[12,13]$. All children aged six months to 10 years and their primary caregivers (individuals with primary responsibility for each child's care) were enrolled in August-September 2011 from 100 households randomly selected from an enumeration census of all households in the sub-county. Recruitment was dynamic such that eligible children reaching six months were enrolled and children reaching 11 years were withdrawn. Households with no remaining study participants were withdrawn and replaced. Participants were followed for all healthcare needs at the study clinic for seven days a week over 36 months, until September 2014. All study participants were provided a LLIN at enrollment and compliance was $>99 \%$ by self-report at the time of routine clinic visits.

New episodes of malaria were diagnosed by passive case detection. Individuals presenting with a fever or history of fever within the past $24 \mathrm{~h}$ with a positive blood smear were treated with artemether-lumefantrine (uncomplicated malaria) or quinine (complicated malaria). In addition, participants were invited to make a routine visit to the study clinic every three months. At each of these visits, a thick blood smear was taken to assess for parasitaemia. Thick and thin blood smears were stained with $2 \%$ Giemsa and read blind. Blood smears were considered negative when the examination of 100 high power fields did not reveal asexual parasites. All blood slides were read twice and discrepancies resolved by a third reviewer. In addition, all positive blood smears 
with a parasite densities $\leq 20000 / \mu$ l based on the field readings were re-read by an expert microscopist based in Kampala and had to be confirmed to be considered positive in the final analyses.

Indoor human biting rate (HBR), the number of adult female Anopheles caught per house per night, was measured by one monthly catch per home using a Centers for Disease Control and Prevention (CDC) light trap (Model 512; John W. Hock Company, Gainesville, FL). CDC light traps were positioned $1 \mathrm{~m}$ above the floor at the foot of the bed, where a study participant slept under a LLIN, and were set from $7.00 \mathrm{pm}$ until $7.00 \mathrm{am}$.

\section{Conceptual framework}

Collection of socioeconomic data was guided by a predefined conceptual framework (Fig. 1), hypothesising that: (1) relative agricultural success is associated with higher SEP (Box 1), (2) higher SEP reduces malaria risk and (3) the effect of SEP on malaria risk is mediated by treatment-seeking behaviour, house type and food security among other variables.

\section{Household and women's surveys}

Socioeconomic data were collected during three surveys: (i) a household survey conducted at baseline, (ii) a second household survey conducted after 24 months of follow-up in September-October 2013 and (iii) a women's survey, administered as a separate structured questionnaire alongside the second household survey. Both household surveys were administered to one designated adult respondent from each household, if they met four inclusion criteria: (1) usually resident, (2) present in the sampled household the night before

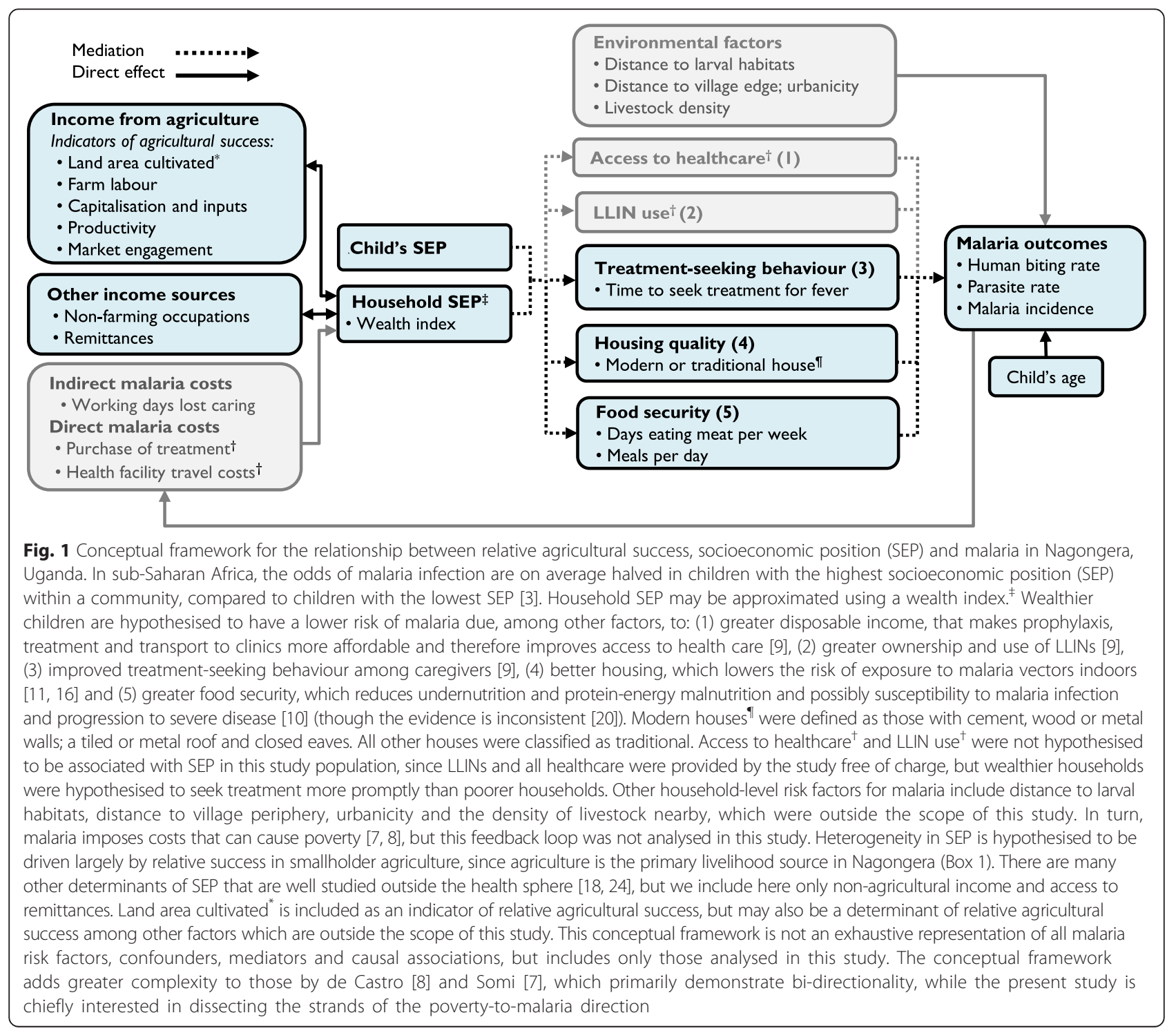




\section{Box 1. Understanding poverty reduction in rural Uganda}

In low income countries, poverty reduction generally involves decreased livelihood vulnerability, changes in livelihood activities and increased incomes through a shift towards more productive activities [24]. In rural areas, such activities are typically grounded in agriculture, later diversifying to include non-agricultural activities

[17]. Indeed, agriculture is the primary source of livelihood for much of the rural poor in developing countries. In Uganda, the net output of agriculture comprised $24 \%$ of gross domestic product and the agricultural sector provided two-thirds of total employment in 2010 [31]. In much of rural Africa, heterogeneity in socioeconomic position (SEP) can therefore be understood by examining relative success in smallholder agriculture [17]. Often mistaken as homogeneous, rural African populations encompass many classes with different ambitions and constraints. Relative agricultural success reflects the degree to which smallholder farmers successfully derive a living from the land, sometimes using agricultural income to upscale other enterprises. Agricultural success can be approximated using indicators such as farm size, production performance (yield) and labour hire, or by examining the processes of accumulation and production that allow people to 'hang in' (maintain livelihood levels through farming), 'step up' (invest in assets to expand current activities, increase production and improve livelihoods), or to accumulate resources to 'step out' (move into different activities with higher returns) $[18,24]$.

the survey, (3) aged at least 18 years and (4) agreed to provide informed written consent. The women's survey was administered to all adult women of childbearing age (1849 years), resident in each study household, who met three inclusion criteria: (1) usual female resident, (2) present in the sampled household the night before the survey, (3) agreed to provide informed written consent. Households were excluded if no adult respondent could be located on more than three occasions over two weeks.

Variables for the wealth index were collected in the first household survey (main mode of transport to the health facility) and in the second household survey (all other wealth index variables). House construction was recorded through separate house visits by the entomology field teams during 2013 and validated by the second household survey. Agricultural data were collected in the second household survey. The educational status of each child's mother or the eldest female caregiver in each child's household was recorded in the women's survey.

\section{Data analysis}

Data were collected using standardised record forms entered into Microsoft Access for follow-up of study participants and using a paperless system for the household and women's surveys.

\section{Wealth index and house type}

We used a wealth index previously developed for the study population [15]. In brief, principal component analysis (PCA) was used to create the wealth index from nine variables: ownership of (1) mobile telephones, (2) radios, (3) clocks, (4) cupboards, (5) sofas and (6) tables; (7) number of people per sleeping room; (8) access to an improved toilet and (9) main mode of transport to the health facility. Households were ranked by wealth scores and grouped into tertiles to give a categorical measure of SEP. A definition of house type previously developed for the study area was used [16]. Main wall material, main roof material and eave type were used to classify homes as either modern (wood, cement or brick walls; a metal or tiled roof and closed eaves) or traditional (all other homes).

There were four components within the analysis that evaluated: (1) the association between agricultural success and SEP, (2) risk factors for human biting rate (HBR), parasite prevalence and incidence of clinical malaria, including SEP, (3) spatial clustering of socioeconomic variables and (4) mediators of the association between SEP and parasite prevalence.

(1)Association between agricultural success and SEP: Agricultural success was estimated through household survey questions on indicators within five domains, after Oya [17] and Scoones [18] (Fig. 1): (1) land area cultivated, (2) farm labour, (3) capitalisation (access to advanced means of production, such as pesticides or heavy machinery), (4) productivity and (5) market engagement (proportion of produce sold versus used for own consumption). Cross tabulations and Pearson's chi-square test were used to explore the associations between indicators of agricultural success, wealth index tertiles and food security.

(2)Risk factors for malaria: For each risk factor, including SEP, we modelled its association with HBR, parasite prevalence and incidence of clinical malaria. Negative binomial regression was used to model the number of Anopheles caught per household per night and the number of malaria cases per child with the number of catch nights and person years included as offset terms. The odds of malaria infection at the time of each routine clinic visit were modelled using logistic regression. For the clinical outcomes (parasite prevalence and malaria incidence), age and gender were included in the model as covariates and robust standard errors were used to adjust 
for repeat measures (clustering) at the household level.

(3) Spatial analysis of socioeconomic variables: Spatial autocorrelation (clustering) of three socioeconomic variables (cultivated land area, wealth index scores and house type) was explored at global scale using univariate Moran's $I$ and at local scale using univariate Anselin Moran's $I$ (Additional file 2).

(4) Mediation of the association between SEP and malaria: We aimed to calculate the effect of SEP on malaria infection risk that is mediated through treatment-seeking behaviour, house type and food security using the algorithm described by Imai [19] (Additional file 3; Fig. 1). This algorithm makes two ignorability assumptions which in practice will hold if there is no unmeasured confounding of the association between exposure and mediator, exposure and outcome or mediator and outcome, and there is no reverse causation.

\section{Results}

\section{Study population}

A total of 333 children in 107 total households were enrolled between August 2011 and September 2014 (Fig. 2). The mean age of study children during follow-up was 5.7 years and 153 (46\%) were female.

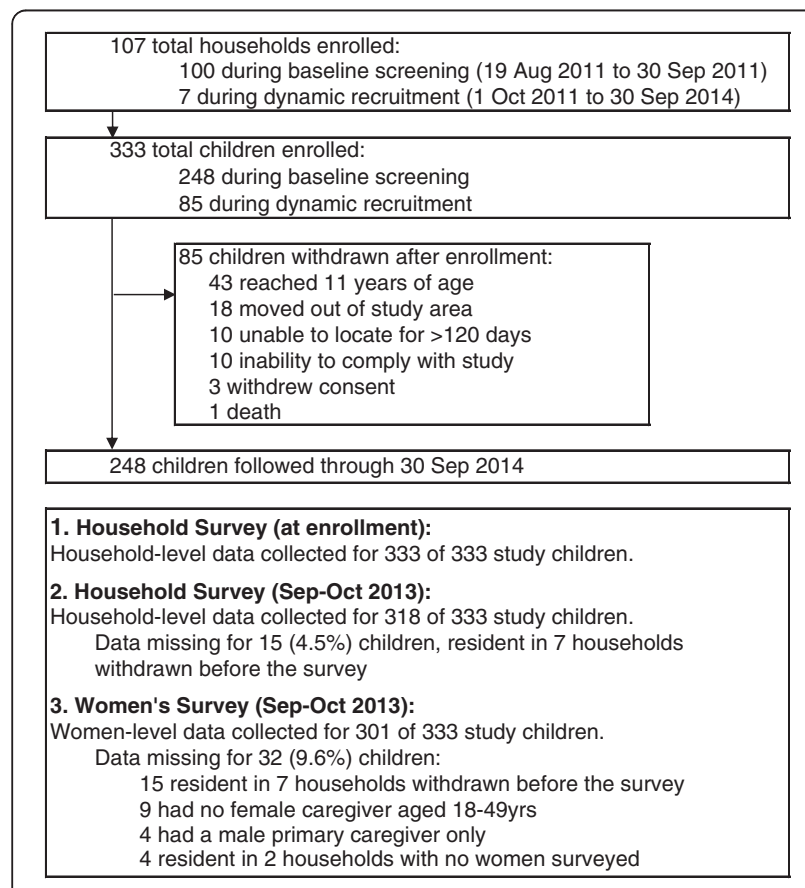

Fig. 2 Study profile for a cohort of children aged 6 months to ten years $(N=333)$ in Nagongera, Uganda

\section{Wealth index}

The first principal component explained $29.3 \%$ of overall variability in the asset variables. The weight assigned to each variable was: cupboard (0.45), clock (0.43), sofa (0.41), table (0.37), mobile (0.30), toilet access (0.29), radio (0.29), people per sleeping room (0.19), mode of transport to health facility $(0.10)$. Wealthier households generally sought treatment for fever faster and had better education, housing and food security than poorer households (Table 1 ).

\section{Association between agricultural success and SEP}

All households grew crops and agriculture was the primary source of income for $74 \%$ of households. Wealthier households cultivated more land and had greater agricultural income, compared to the lowest tertiles. Wealthier households and those with larger farms also employed more farm labour, were more likely to use an oxplough, owned more tropical livestock units and sold a greater proportion of their crops than poorer households and those with smaller farms (Table 2). Households with larger farms reported fewer problems getting food to eat $(P=0.001)$ and ate meat more frequently $(P=0.002)$.

\section{Risk factors for malaria Human biting rate (HBR)}

A total of 124,746 adult female Anopheles were caught over 3489 collection nights, yielding an overall HBR of 35.8 Anopheles per house per night. HBR was $29 \%$ lower in the wealthiest households (highest versus lowest wealth index tertile: Incidence Rate Ratio (IRR) 0.71, $95 \%$ confidence intervals $(C I) 0.54-0.93, P=0.01)$ and $47 \%$ lower in households with good house construction, controlling for household SEP (modern versus traditional housing: adjusted IRR 0.53, $95 \%$ CI 0.40-0.69, P $<0.001$ ) (Table 3).

\section{Malaria infection}

A total of 3367 routine blood smears were taken of which 1037 (30.8\%) were positive. All participants contributed at least one smear. Controlling for age and gender, the odds of infection were $49 \%$ lower in children living in modern housing (modern versus traditional housing: adjusted Odds Ratio (OR) 0.51, 95 \% CI 0.36$0.71, P<0.001$ ), $48 \%$ lower in wealthier children (highest versus lowest wealth index tertile: adjusted $O R 0.52$, $95 \% C I 0.35-0.78, P=0.001)$ and $36 \%$ lower in children with good food security (meat eaten $3-7$ versus $0-2$ days per week: adjusted $O R \quad 0.64,95 \% C I 0.47-0.88, P=$ 0.007) (Table 4). 
Table1 Characteristics of study participants and households in Nagongera, Uganda

\begin{tabular}{|c|c|c|c|c|}
\hline \multirow[t]{2}{*}{ Characteristic } & \multicolumn{4}{|c|}{ Wealth index tertile (\%) } \\
\hline & Poorest & Middle & Highest & $P$ \\
\hline \multicolumn{5}{|l|}{ Characteristics of children $(\mathrm{N}=333)$} \\
\hline Mean age during follow up in years & 5.6 & 5.6 & 5.8 & 0.61 \\
\hline Female & 41.8 & 45.8 & 50.5 & 0.45 \\
\hline Female caregiver completed at least primary education ${ }^{a}$ & 7.5 & 26.0 & 27.6 & 0.003 \\
\hline Female caregiver seeks fever treatment on same day ${ }^{b}$ & 28.8 & 8.2 & 42.0 & $<0.001$ \\
\hline \multicolumn{5}{|l|}{ Characteristics of households $(N=100)$} \\
\hline Distance to nearest health facility $<3 \mathrm{~km}$ & 54.3 & 40.6 & 48.5 & 0.53 \\
\hline Health expenditure $\geq 25 \%$ of total household expenditure & 8.6 & 6.3 & 18.2 & 0.26 \\
\hline Modern house ${ }^{c}$ & 0.0 & 25.0 & 48.5 & $<0.001$ \\
\hline Meat eaten $\geq 3$ days per week & 17.1 & 37.5 & 66.7 & $<0.001$ \\
\hline Meals per day $\geq 3$ & 2.9 & 28.1 & 54.6 & $<0.001$ \\
\hline Land area cultivated $\geq 1.6 \mathrm{ha}^{\mathrm{d}}$ & 28.6 & 34.4 & 60.6 & 0.02 \\
\hline
\end{tabular}

${ }^{a}$ Data on female caregiver's education collected for 301 of 333 (90\%) children

${ }^{b}$ Data on female caregiver's treatment-seeking behaviour collected for 191 of 333 (57\%) children

'Modern house: Cement, wood or metal wall; tiled or metal roof and closed eaves. Traditional house: all other houses

${ }^{\mathrm{d}} \mathrm{Ha}=$ hectare; $1.6 \mathrm{ha}=4$ acres

\section{Incidence of clinical malaria}

A total of 2399 episodes of uncomplicated malaria were diagnosed after 802 person years of follow-up, yielding an overall incidence of 3.0 episodes per person year at risk. One participant was withdrawn immediately after enrolment without contributing person time. Controlling for age and gender, malaria incidence was $31 \%$ lower among children with better-educated female caregivers (completed at least primary versus no education: adjusted IRR 0.69, $95 \%$ CI 0.53-0.91, P=0.008). Malaria incidence was not associated with any other risk factors explored (Table 4).

\section{Spatial analysis of socioeconomic variables}

Across the whole study area, there was no evidence of clustering of cultivated land area, house type or wealth index (Additional file 2). However, there was local clustering of these three variables, with a cluster of modern housing and high wealth index scores in study houses located in a small town (Nagongera) in the south east of the study area (Fig. 3).

\section{Mediation of the association between SEP and malaria}

There was evidence that the total effect of SEP on malaria infection risk in children was partly explained by differences in house quality $(24.9 \%$, $95 \%$ CI $15.8 \%-58.6 \%)$ and food security $(18.6 \%, 95 \% C I$ $11.6 \%$ - $48.3 \%)$ between wealthier and poorer homes. Treatment-seeking behaviour was excluded from the mediation analysis since data on time to seek treatment were available for 191 (57 \%) children only (Table 5 ).

\section{Discussion}

We investigated the association between socioeconomic position (SEP), its determinants, and malaria in children in a rural, high-transmission setting in Uganda. Households with greater agricultural success had higher SEP. In turn, households and children of higher SEP were exposed to a $29 \%$ lower HBR and had $48 \%$ lower odds of malaria infection than the poorest. Finally, there was evidence that the association between SEP and malaria infection was explained partly by house type and food security. Our findings concur with observations elsewhere in sub-Saharan Africa (SSA) that the odds of malaria infection are on average doubled in children with the lowest SEP (as measured by household wealth index scores or parent's educational status or occupation) compared to children with the highest SEP within the same community [3]. Socioeconomic factors may be as influencial in malaria transmission today in Uganda as they were historically in North America and Europe [4].

To our knowledge, the present study is the first to use mediation analysis to explore the causal pathways by which poverty may cause malaria. First, the analysis suggests that house type may explain part of the association between SEP and malaria infection risk, consistent with previous observations that well-built housing, with closed eaves and modern wall and roof materials, is associated with lower malaria risk through reduced mosquito house entry $[11,16]$. Second, we observed that food security may also mediate the poverty-malaria association. While findings on the relationship between nutrition and malaria are inconsistent [20], there is evidence that undernutrition may be associated with greater susceptibility to malaria infection and 
Table 2 Association between agricultural success, land area cultivated and household socioeconomic position in 100 households in Nagongera, Uganda

\begin{tabular}{|c|c|c|c|c|c|c|c|}
\hline \multirow[t]{2}{*}{ Indicator } & \multicolumn{3}{|c|}{ Land area cultivated (\%) } & \multicolumn{4}{|c|}{ Wealth index tertile (\%) } \\
\hline & $<1.6 \mathrm{ha}^{\mathrm{a}}(N=59)$ & $\geq 1.6$ ha $(N=41)$ & $P$ & Poorest $(N=35)$ & Middle $(N=32)$ & Highest $(\mathrm{N}=33)$ & $P$ \\
\hline \multicolumn{8}{|l|}{ Land area cultivated } \\
\hline Land area cultivated $\left(\geq 1.6\right.$ ha vs $<1.6$ ha) ${ }^{a}$ & - & - & - & 28.6 & 34.4 & 60.6 & 0.02 \\
\hline Land ownership (all owned vs part rented) & 35.6 & 51.2 & 0.12 & 45.7 & 34.4 & 45.5 & 0.57 \\
\hline \multicolumn{8}{|l|}{ Farm labour } \\
\hline Hired farm labour & 50.9 & 61.0 & 0.32 & 42.9 & 43.8 & 78.8 & 0.004 \\
\hline $\begin{array}{l}\text { Total number of farm workers } \\
\text { ( } \geq 6 \text { people vs } 0-5 \text { people) }\end{array}$ & 25.4 & 51.2 & 0.008 & 17.1 & 31.3 & 60.6 & 0.001 \\
\hline \multicolumn{8}{|l|}{ Capitalisation and inputs } \\
\hline Ox-plough used, past 12 months & 33.9 & 73.2 & $<0.001$ & 34.3 & 40.6 & 75.8 & 0.001 \\
\hline $\begin{array}{l}\text { Pesticides and herbicides used, past } \\
12 \text { months }\end{array}$ & 69.5 & 78.1 & 0.34 & 65.7 & 75.0 & 78.8 & 0.46 \\
\hline Access to credit for agriculture & 15.3 & 29.3 & 0.09 & 17.1 & 18.8 & 27.3 & 0.55 \\
\hline \multicolumn{8}{|l|}{ Productivity } \\
\hline $\begin{array}{l}\text { TLUb per household member } \\
(\geq 0.05 \text { vs }<0.05 \text { TLU per person) }\end{array}$ & 33.9 & 61.0 & 0.007 & 37.1 & 34.4 & 63.6 & 0.03 \\
\hline \multicolumn{8}{|l|}{ Market engagement } \\
\hline $\begin{array}{l}\text { Total income from crop sales, past } 12 \\
\text { months }{ }^{c}\end{array}$ & 27.1 & 51.2 & 0.002 & 20.0 & 31.3 & 60.6 & 0.01 \\
\hline $\begin{array}{l}\text { Total income from crop and livestock } \\
\text { sales, past } 12 \text { months }{ }^{d}\end{array}$ & 18.6 & 40.0 & 0.001 & 11.4 & 18.8 & 53.1 & 0.001 \\
\hline Proportion of crops sold ( $\geq 25 \%$ vs <25 \%) & 22.0 & 48.8 & 0.005 & 17.1 & 31.3 & 51.5 & 0.01 \\
\hline \multicolumn{8}{|l|}{ Non-agricultural income } \\
\hline Main source of household income $e^{e}$ & - & - & - & 11.4 & 15.6 & 21.2 & 0.27 \\
\hline Remittances received, past 12 months & - & - & - & 5.7 & 12.5 & 27.3 & 0.04 \\
\hline
\end{tabular}

${ }^{\mathrm{a}} \mathrm{Ha}=$ hectare; $1.6 \mathrm{ha}=4$ acres

${ }^{\mathrm{b}}$ Tropical Livestock Units (TLUs) are a standardised method for quantifying livestock. One TLU corresponds approximately to $250 \mathrm{~kg}$ animal weight and total

TLUs are calculated by assigning region-specific weights to different livestock types. The following weights were assigned, after Chilonda and Otte: 0.5 per cattle,

0.1 per goat, 0.01 per poultry or rabbit [32]

'Total income from all crop sales in the past 12 months: $\geq$ US\$ 80 versus $<$ US\$ 80 (2013 prices)

dTotal income from crop and livestock sales in the past 12 months: $\geq$ US $\$ 120$ versus $<$ US $\$ 120$ (2013 prices)

${ }^{\mathrm{e}}$ Main source of household income: skilled labour versus remittances, agriculture or manual labour

progression to severe disease [10] and that proteinenergy malnutrition is associated with greater malaria morbidity and mortality [21]. Indeed, a previous study in our study district found that stunting (an indicator of chronic malnutrition) was associated with a higher incidence of clinical malaria in children [22]. Conversely, it is possible that our measure of food security was more of a proxy for SEP than nutritional status [23].

Identifying factors potentially mediating between SEP and malaria provides evidence of a biologically plausible mechanism for causality, yet the mediation analysis was subject to a number of limitations. First, house quality

Table 3 Socioeconomic risk factors for human biting rate in 100 households in Nagongera, Uganda

\begin{tabular}{|c|c|c|c|c|}
\hline Characteristic & & HBR (Total collection nights) ${ }^{a}$ & $\operatorname{IRR}(95 \% C C)^{\mathrm{b}}$ & $P$ \\
\hline \multirow[t]{3}{*}{ Wealth index tertile } & Poorest & $41.5(1136)$ & 1 & 0.01 \\
\hline & Middle & $34.4(1132)$ & $0.86(0.65-1.13)$ & \\
\hline & Highest & $28.8(1110)$ & $0.71(0.54-0.93)$ & \\
\hline \multirow[t]{2}{*}{ House type $^{c}$} & Traditional & $40.5(2690)$ & 1 & $<0.001$ \\
\hline & Modern $^{d}$ & 19.9 (799) & $0.53(0.40-0.69)$ & \\
\hline
\end{tabular}

aBR: Human biting rate: total adult female Anopheles caught/total collection nights

bIRR: Incidence rate ratio; $\mathrm{Cl}$ : Confidence interval

'IRR for this variable was adjusted for household wealth

${ }^{\mathrm{d}}$ Modern house: Cement, wood or metal wall; tiled or metal roof and closed eaves. Traditional house: all other houses 
Table 4 Socioeconomic risk factors for malaria in children aged six months to 10 years in Nagongera, Uganda

\begin{tabular}{|c|c|c|c|c|c|c|c|}
\hline \multirow[t]{2}{*}{ Characteristic } & & \multicolumn{3}{|l|}{ Malaria infection } & \multicolumn{3}{|c|}{ Incidence of clinical malaria } \\
\hline & & $\begin{array}{l}\text { PR (Total blood } \\
\text { smears) }\end{array}$ & OR $(95 \% C l)^{b}$ & $P$ & $\begin{array}{l}\text { Malaria incidence } \\
\text { (total person years) }^{c}\end{array}$ & $\operatorname{IRR}\left(95 \%\right.$ Cl) ${ }^{\mathrm{d}}$ & $P$ \\
\hline \multirow[t]{3}{*}{ Mean age during follow-up } & $6 \mathrm{~m}$ to $<3$ years & $19.2(657)$ & 1 & $<0.001$ & $4.1(134)$ & 1 & $<0.001$ \\
\hline & 3 to $<5$ years & $27.6(699)$ & $1.60(1.18-2.18)$ & & $4.2(177)$ & $1.01(0.85-1.19)$ & \\
\hline & 5 to $<11$ year & $35.7(2011)$ & $2.34(1.77-3.09)$ & & $2.3(491)$ & $0.54(0.46-0.65)$ & \\
\hline \multirow[t]{2}{*}{ Gender } & Female & $29.9(1518)$ & 1 & 0.54 & $2.7(361)$ & 1 & 0.12 \\
\hline & Male & $31.5(1849)$ & $1.07(0.86-1.35)$ & & $3.2(441)$ & $1.13(0.97-1.32)$ & \\
\hline \multirow[t]{3}{*}{ Wealth index tertile } & Lowest & $38.4(1087)$ & 1 & 0.001 & $3.0(258)$ & 1 & 0.66 \\
\hline & Middle & $29.6(1170)$ & $0.65(0.48-0.87)$ & & $3.1(280)$ & $1.12(0.90-1.40)$ & \\
\hline & Highest & $25.3(1010)$ & $0.52(0.35-0.78)$ & & $2.9(241)$ & $1.05(0.83-1.34)$ & \\
\hline \multirow[t]{3}{*}{ Female caregiver's level of education } & None & $33.4(788)$ & 1 & 0.21 & $3.5(188)$ & 1 & 0.005 \\
\hline & Incomplete $1^{\text {ry }}$ & $31.7(1703)$ & $0.96(0.68-1.36)$ & & $3.0(406)$ & $0.83(0.69-1.01)$ & \\
\hline & $1^{\text {ry }}$ or higher & $26.6(593)$ & $0.74(0.48-1.15)$ & & $2.4(140)$ & $0.69(0.53-0.91)$ & \\
\hline \multirow[t]{2}{*}{ Distance to health facility } & $3-6$ km & 33.4 (1994) & 1 & 0.07 & $2.9(474)$ & 1 & 0.56 \\
\hline & $0-2 \mathrm{~km}$ & $27.1(1373)$ & $0.75(0.55-1.02)$ & & $3.1(328)$ & $1.06(0.87-1.29)$ & \\
\hline \multirow{2}{*}{$\begin{array}{l}\text { Time for female caregiver to seek } \\
\text { treatment for fever }\end{array}$} & $\geq 1$ day & $29.5(1434)$ & 1 & 0.55 & $3.3(342)$ & 1 & 0.31 \\
\hline & Same day & $27.5(509)$ & $0.86(0.51-1.42)$ & & $2.5(120)$ & $0.87(0.67-1.13)$ & \\
\hline \multirow{2}{*}{$\begin{array}{l}\text { Proportion of household expenditure } \\
\text { on health }\end{array}$} & $<25 \%$ & $31.0(3059)$ & 1 & 0.65 & $3.1(730)$ & 1 & 0.15 \\
\hline & $25-50 \%$ & $34.1(208)$ & $1.15(0.63-2.10)$ & & $2.0(49)$ & $0.73(0.48-1.12)$ & \\
\hline \multirow[t]{2}{*}{ House type ${ }^{e}$} & Traditional & $32.9(2794)$ & 1 & $<0.001$ & $3.0(665)$ & 1 & 0.67 \\
\hline & Modern & $20.4(573)$ & $0.51(0.36-0.71)$ & & $2.7(136)$ & $0.93(0.68-1.28)$ & \\
\hline \multirow[t]{2}{*}{ People per sleeping room } & >2 people & $31.9(2752)$ & 1 & 0.24 & $3.1(656)$ & 1 & 0.29 \\
\hline & 0-2 people & $27.0(515)$ & $0.78(0.51-1.19)$ & & $2.6(123)$ & $0.86(0.64,1.14)$ & \\
\hline \multirow[t]{2}{*}{ Days eating meat per week } & $0-2$ days & $34.6(2123)$ & 1 & 0.007 & $3.0(507)$ & 1 & 0.71 \\
\hline & 3-7 days & $24.7(1144)$ & $0.64(0.47-0.88)$ & & $2.9(271)$ & $0.96(0.77-1.20)$ & \\
\hline \multirow[t]{2}{*}{ Meals per day } & 2 meals & 33.1 (2439) & 1 & 0.05 & $3.0(581)$ & 1 & 0.78 \\
\hline & 3-4 meals & $25.6(828)$ & $0.72(0.52-1.00)$ & & 2.9 (197) & $0.96(0.75-1.24)$ & \\
\hline
\end{tabular}

aPR: Plasmodium falciparum parasite rate: total positive blood smears/total blood smears

${ }^{b} \mathrm{OR}$ : Odds Ratio adjusted for age at the time of the blood smear and gender. $\mathrm{Cl}$ Confidence interval

${ }^{\mathrm{C}}$ Malaria incidence per person year: total malaria episodes/total person years at risk

IRR: Incidence Rate Ratio adjusted for mean age during follow-up and gender

${ }^{\mathrm{e}}$ Modern house: Cement, wood or metal wall; tiled or metal roof and closed eaves. Traditional house: all other houses

and food security together accounted for less than half of the association between poverty and malaria infection risk, suggesting that other mediators remain unaccounted for. While treatment-seeking behaviour was excluded from the mediation analysis, wealthier households sought treatment for fever more promptly than poorer households, so this variable merits future evaluation as a potential mediator. Additional potential mediators may include distance of households to the village periphery, housing density and, given the local clustering of wealthier households, malaria risk in neighbouring households. Education level, while considered an indicator of SEP [15], arguably could also lie on the mediation pathway. Therefore our conceptual framework and analysis were not exhaustive and provide only a preliminary exploration of the complex relationships linking poverty and malaria. Second, the assumptions underlying the mediation analysis may not have been fully met. For example, the costs of malaria can worsen poverty, resulting in reverse causality $[7,8]$, and the relationship between SEP and malaria may be confounded by environmental factors such as distance to larval habitats (alternatively, location might be on the causal pathway between SEP and malaria). While we aimed to omit from the wealth index variables directly associated with malaria [15], some of the included assets may have been associated with both SEP and house type (e.g. sofa ownership or toilet access). Third, we did not observe any association between SEP and incidence of clinical malaria and the interpretation of this finding is unclear. 

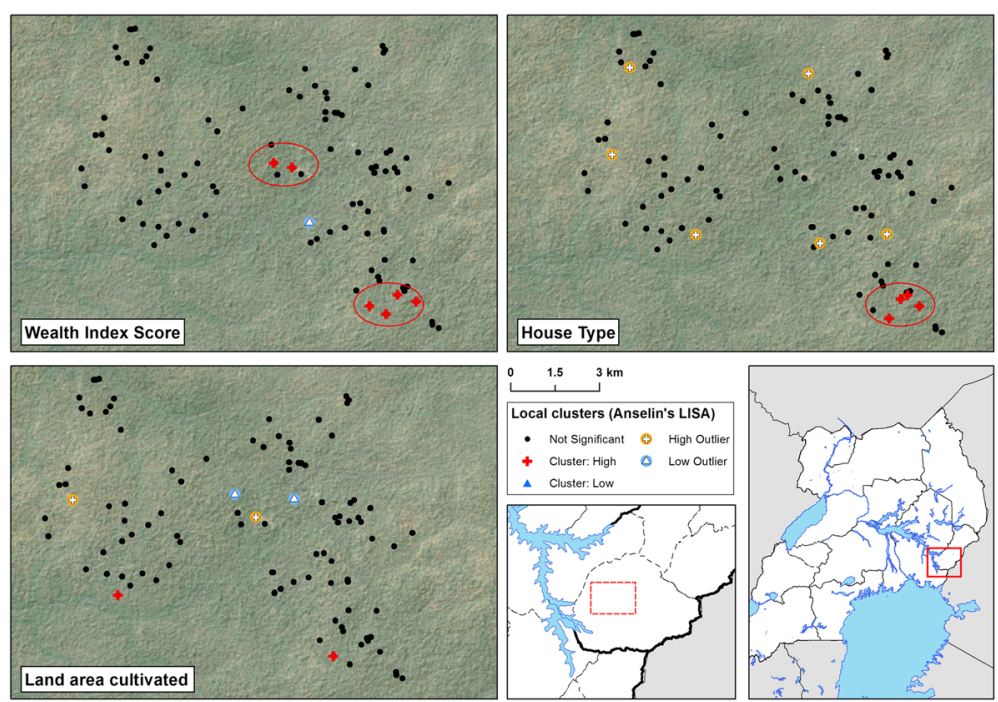

Fig. 3 Local cluster maps of wealth index score, house type and cultivated land area in 100 households in Nagongera, Uganda. Maps show results from univariate Local Indicator of Spatial Association (LISA) analysis. A cluster of high wealth index scores overlapping with a cluster of modern housing is located in the south-east of the study area. Houses were classified as modern (cement, wood or metal walls; a tiled or metal roof and closed eaves) or traditional (all other houses). Wealth index score and land area cultivated were modelled as continuous variables

To identify potential cross-over between development interventions and malaria control, we sought to understand better the heterogeneity in SEP in the study area. Overall we found that SEP was associated with increased odds of malaria infection. In turn, SEP was associated with relative agricultural success, consistent with agriculture being a major livelihood source in Nagongera as in much of rural Africa [18, 24]. We also observed that wealthier households had larger farms and were overall more successful in agriculture than poorer households. Of course, wealthier households may invest more in agriculture and other enterprises, improving their overall productivity. Yet it is also feasible that agricultural productivity limits household wealth and that land access constrains productivity in Nagongera, since there is extensive land fragmentation stemming from the division of land over generations, which is likely to continue as the Ugandan population expands from 39 million in
2015 to an estimated 102 million in 2050 [25]. Elsewhere in SSA, rural poverty has been linked to lower vegetation index scores, remoteness and poor soil fertility [26]. While the conclusions that may be drawn from our observational study are limited, our findings highlight the importance of understanding malaria transmission within the wider social and ecological landscape.

By examining the relationship between poverty and malaria, practical steps towards multisectoral intervention may be identified. First, there may be overlap between poverty reduction and malaria control [3]. If this is the case, interventions such as Farmer Field Schools (a group-based education approach) might be targeted in areas where agriculture is an important livelihood source to increase production and marketing capacity while incorporating training in Integrated Pest and Vector Management [27]. If land access constrains productivity, diversification into non-agricultural activities

Table 5 Mediation analysis of the association between socioeconomic position and malaria infection in children aged six months to 10 years in Nagongera, Uganda

\begin{tabular}{|c|c|c|c|c|}
\hline \multirow{2}{*}{$\begin{array}{l}\text { Mediating } \\
\text { variable }^{a}\end{array}$} & \multicolumn{3}{|c|}{ Risk difference $(95 \% \mathrm{Cl})^{\mathrm{b}}$, high versus low SEPc } & \multirow{2}{*}{$\begin{array}{l}\text { Proportion of total effect } \\
\text { of SEP that occurs through } \\
\text { mediator, \% ( } 95 \% \text { Cl) }\end{array}$} \\
\hline & Direct effect of SEP & Effect of SEP through mediator & Total effect of SEP & \\
\hline House type $^{d}$ & $-8.6(-15.6,-2.1)$ & $-2.9(-5.5,-0.8)$ & $-11.5(-18.1,-4.9)$ & $24.9(15.8,58.6)$ \\
\hline Food security ${ }^{\mathrm{e}}$ & $-9.2(-16.9,-2.2)$ & $-2.1(-5.3,0.0)$ & $-11.4(-18.4,-4.4)$ & $18.6(11.6,48.3)$ \\
\hline
\end{tabular}

${ }^{\mathrm{a}}$ Treatment-seeking behaviour was excluded from the mediation analysis since data on time to seek treatment were available for 191 of 333 ( $57 \%$ ) children only ${ }^{b}$ Risk difference adjusted for gender, age ( $<5$ years vs 5-11 year) and clustering at the household level

'SEP: household socioeconomic position, modelled as a binary variable (middle and highest wealth index tertiles versus lowest wealth index tertile)

dHouse type: modern (cement, wood or metal walls; and tiled or metal roof; and closed eaves) versus traditional (all other houses)

e Food security: Meat consumed 3-7 days versus 0-2 days per week 
may be necessary, alongside interventions to improve productivity and market access among remaining farmers. Second, since house quality is associated with malaria risk, malaria control progammes could work with other sectors to scale-up 'healthy' housing [28]. Possible strategies may include microfinance initiatives, education and the use of model houses to encourage good house design, or collaboration with other ministries and the private sector [29]. Third, should good nutrition be protective against malaria, nutritionsensistive interventions - including those related to agriculture and food security - may be complementary to malaria control.

Our study has a number of limitations. First, the mediation analysis was based on untestable assumptions (Additional file 3). Should these assumptions not hold, this would limit confidence in house quality and food security being mediators of the SEP-malaria relationship and in their associated mediating effects. Throughout our analysis, we assume that SEP affects malaria risk, yet reverse causality from malaria risk to SEP and agricultural productivity is highly probable $[7,8,30]$. Second, the conceptual framework was not an exhaustive representation and we were unable to investigate all causal pathways linking SEP and malaria, nor all potential determinants of poverty. Third, the wealth index is an imperfect metric and its representation of underlying SEP is influenced by the variables included in the index [15]. Fourth, our spatial analysis modelled few variables relevant to malaria. Finally, we studied only one population at one time point, so the findings require future validation in this and other settings. Despite the methodological challenges, it is hoped that our analysis offers a preliminary insight into the complex relationship between poverty and malaria, providing a framework for future interdisciplinary research.

\section{Conclusions}

Housing improvements and agricultural development interventions to reduce poverty merit further investigation as multisectoral interventions against malaria. Further interdisplinary research is needed to understand fully the complex pathways between poverty and malaria and to develop strategies for sustainable malaria control.

\section{Additional files}

Additional file 1: Multilingual abstracts in the six official working languages of the United nations. (PDF $823 \mathrm{~kb}$ )

Additional file 2: Implementation of the spatial autocorrelation analysis. (PDF $857 \mathrm{~kb}$ )

Additional file 3: Implementation of the mediation analysis. (PDF $280 \mathrm{~kb}$ )

Additional file 4: Data files. (ZIP $15 \mathrm{~kb}$ )

\section{Abbreviations}

$\mathrm{Cl}$, confidence interval; $\mathrm{HBR}$, human biting rate; IRR, incidence rate ratio; LISA, Local Indicator of Spatial Association; LLIN, long-lasting insecticide-treated bednet; OR, odds ratio; PCA, principal component analysis; SEP, socioeconomic position; SSA, Sub-Saharan Africa; USA, United States of America

\section{Acknowledgements}

We are grateful to the study participants and their families. We thank the Infectious Diseases Research Collaboration (IDRC) for administrative and technical support and the Malaria Centre at the London School of Hygiene \& Tropical Medicine.

\section{Funding}

This work was supported by the Leverhulme Centre for Integrative Research in Agriculture and Health; US National Institures of Health (U19AI089674); Research and Policy for Infectious Disease Dynamics (RAPIDD) program of the Science and Technology Directorate, US Department of Homeland Security, the Fogarty International Center (US National Institutes of Health); and the Bill \& Melinda Gates Foundation (OPP1053338). The funding bodies had no role in the design of the study and collection, analysis, and interpretation of data and in writing the manuscript.

\section{Availability of data and materials}

The authors confirm that all data underlying the findings are fully available without restriction. All relevant data are available in Additional file 4.

\section{Authors' contributions}

LST, EA, SGS, MK, GD and SWL conceived and designed the study. LST, EA, JR, SGS, MK and GD collected the data. LST and CB analysed the data and JC conducted the spatial analysis. LST and JC prepared the first draft of the manuscript. All authors had access to study data and reviewed the final manuscript.

\section{Competing interests}

The authors declare that they have no competing interests.

\section{Ethics approval and consent to participate}

Ethical approval for the study was given by the Uganda National Council for Science and Technology; Makerere University School of Medicine Research and Ethics Committee; University of California, San Francisco Committee for Human Research and London School of Hygiene and Tropical Medicine Ethics Committee.

\section{Author details}

${ }^{1}$ Department of Disease Control, London School of Hygiene \& Tropical Medicine, London, UK. ${ }^{2}$ Big Data Institute, Nuffield Department of Medicine, University of Oxford, Oxford, UK. ${ }^{3}$ Infectious Diseases Research Collaboration, Kampala, Uganda. ${ }^{4}$ Department of Clinical Research, London School of Hygiene and Tropical Medicine, London, UK. ${ }^{5}$ School of Medicine, Makerere University College of Health Sciences, Kampala, Uganda. ${ }^{6} \mathrm{MRC}$ Tropical Epidemiology Group, London School of Hygiene and Tropical Medicine, London, UK. ${ }^{7}$ Department of Economics, SOAS, University of London, London, UK. ${ }^{8}$ Department of Medicine, University of California, San Francisco, USA. ${ }^{9}$ School of Biological and Biomedical Sciences, Durham University, Durham, UK.

Received: 18 February 2016 Accepted: 24 June 2016

Published online: 04 August 2016

\section{References}

1. WHO. World Malaria Report. Geneva: World Health Organization; 2015

2. Bhatt S, Weiss DJ, Cameron E, Bisanzio D, Mappin B, Dalrymple U, Battle KE, Moyes CL, Henry A, Eckhoff PA, Wenger EA, Briët O, Penny MA, Smith TA, Bennett A, Yukich J, Eisele TP, Griffin JT, Fergus CA, Lynch M, Lindgren F, Cohen JM, Murray CL, Smith DL, Hay SI, Cibulskis RE, Gething PW. The effect of malaria control on Plasmodium falciparum in Africa between 2000 and 2015. Nature. 2015;526:207-11.

3. Tusting LS, Willey B, Lucas H, Thompson J, Kafy HT, Smith R, Lindsay SW. Socioeconomic development as an intervention against malaria: a systematic review and meta-analysis. Lancet. 2013;382(9895):834. 
4. Bruce-Chwatt $L$, de Zulueta J. The rise and fall of malaria in Europe. London: Oxford University Press; 1980.

5. RBM/UNDP. Multisectoral Action Framework for Malaria. Geneva: Roll Back Malaria/United Nations Development Programme; 2013.

6. RBM. Action and Investment to defeat Malaria 2016-2030 (AIM). Geneva: Roll Back Malaria Partnership; 2015.

7. Somi MF, Butler JRG. Is there evidence for dual causation between malaria and socioeconomic status? Findings from rural Tanzania. Am J Trop Med Hyg. 2007;77:1020-7

8. de Castro MC, Fisher MG. Is malaria illness among young children a cause or a consequence of low socioeconomic status? Evidence from the United Republic of Tanzania. Malar J. 2012;11:161.

9. Barat LM, Palmer N, Basu S, Worrall E, Hanson K, Mills A. Do malaria contro interventions reach the poor? Am J Trop Med Hyg. 2004;71:174-8.

10. Caulfield LE, Richard S, Black RE. Undernutrition as an underlying cause of malaria morbidity and mortality in children less than five years old. Am J Trop Med Hyg. 2004;71:55-63.

11. Tusting LS, Ippolito M, Willey B, Kleinschmidt I, Dorsey G, Gosling RD, Lindsay SW. The evidence for improving housing to reduce malaria: a systematic review and meta-analysis. Malaria J. 2015;14:209.

12. Maxwell K, Smith DL, Hutchinson R, Kigozi R, Yeka A, Lavoy G, Kamya MR, Staedke SG, Donnelly MJ, Drakeley C, Greenhouse B, Dorsey G, Lindsay SW. Estimating the annual entomological inoculation rate for Plasmodium falciparum transmitted by Anopheles gambiae s.l. using three sampling methods in three sites in Uganda. Malaria J. 2014;13:111.

13. Kamya MR, Arinaitwe E, Wanzira H, Katureebe A, Barusya C, Kigozi SP, Kilama M, Tatem AJ, Rosenthal PJ, Drakeley C, Lindsay SW, Staedke SG, Smith DL, Greenhouse B, Dorsey G. Malaria transmission, infection and disease at three sites with varied transmission intensity in Uganda: implications for malaria control. Am J Trop Med Hyg. 2015;92:903-12.

14. World Bank. Development Indicators. Washington DC: World Bank; 2016. Available: http://data.worldbank.org/indicator. Accessed 10 Feb 2016.

15. Tusting LS, Rek JC, Arinaitwe E, Staedke SG, Kamya M, Bottomley C, Johnston D, Lines J, Dorsey G, Lindsay SW. Measuring socioeconomic inequalities in relation to malaria risk: a comparison of metrics in rural Uganda. Am J Trop Med Hyg. 2016:94:650-8.

16. Wanzirah H, Tusting LS, Arinaitwe E, Katureebe A, Maxwell K, Rek J, Bottomley C, Staedke SG, Kamya M, Dorsey G, Lindsay SW. Mind the gap: house construction and the risk of malaria in Ugandan children. PLOS ONE. 2015:10(1):e0117396.

17. Oya C. The empirical investigation of rural class formation: methodologica issues in a study of large- and middle-scale farmers in Senegal. Hist Mater. 2004;12:289-326.

18. Scoones I, Marongwe N, Mavedzenge B, Murimbarimba F, Mahenehene J, Sukume C. Livelihoods after land reform in Zimbabwe: understanding processes of rural differentiation. J Agrarian Studies. 2012;12:503-27.

19. Imai K, Tingley D, Keele L. A general approach to causal mediation analysis. Psychol Methods. 2010;15:309-34.

20. Sazawal S, Black RE, Ramsan M, Chwaya HM, Stoltzfus RJ, Dutta A, Dhingra U, Kabole I, Deb S, Othman MK, Kabole FM. Effects of routine prophylactic supplementation with iron and folic acid on admission to hospital and mortality in preschool children in a high malaria transmission setting: community-based, randomised, placebo-controlled trial. Lancet. 2006;367: 133-43.

21. Shankar AH. Nutritional modulation of malaria morbidity and mortality. J Infect Dis. 2000;182(1):S37-53.

22. Arinaitwe E, Gasasira A, Verret W, Homsy J, Wanzira H, Kakuru A, Sandison TG, Young S, Tappero JW, Kamya MR, Dorsey G. The association between malnutrition and the incidence of malaria among young HIV-infected and -uninfected Ugandan children: a prospective study. Malar J. 2012;11:90

23. Howe L, Galobardes B, Matijasevich A, Gordon D, Johnston D, Onwujekwe O, Patel R, Webb EA, Lawlor DA, Hargreaves JR. Measuring socio-economic position for epidemiological studies in low- and middle-income countries: a methods of measurement in epidemiology paper. Int J Epidemiol. 2012;41: 871-86

24. Dorward A. Integrating contested aspirations, processes and policy: development as hanging in, stepping up and stepping out. Dev Policy Rev. 2009;27:131-46.

25. World Bank. World Data Bank: Health Nutrition and Population Statistics: Population estimates and projections. 2016. Available: http://databank. worldbank.org/data/home.aspx. Accessed 4 April 2016.
26. Sedda L, Tatem AJ, Morley DW, Atkinson PM, Wardrop NA, Pezzulo C, Sorichetta A, Kuleszo J, Rogers DJ. Poverty, health and satellite-derived vegetation indices: their inter-spatial relationship in West Africa. Int Health. 2015:7(2):99-106.

27. Wielgosz B, Mangheni M, Tsegai D, Ringler C. Malaria in Uganda: improved outcomes when the health sector joins forces with agriculture. Washington DC: International Food Policy Research Institute (IFPRI); 2013.

28. RBM. Consensus statement on housing and malaria. Geneva: Roll Back Malaria Housing and Malaria Work Stream; 2015.

29. Anderson L, Simpson D, Stephens M. Durable housing improvements to fight malaria transmission: Can we learn new strategies from past experience? Atlanta: Habitat for Humanity International Global Programs Department; 2014

30. Fink G, Masiye F. Health and agricultural productivity: Evidence from Zambia. J Health Econ. 2015:42:151-64.

31. World Bank. Africa Development Indicators 2012/13. Washington DC: World Bank; 2013.

32. Chilonda P, Otte J. Indicators to monitor trends in livestock production at national, regional and international levels. Livest Res Rural Dev. 2006;18:117.

\section{Submit your next manuscript to BioMed Central and we will help you at every step:}

- We accept pre-submission inquiries

- Our selector tool helps you to find the most relevant journal

- We provide round the clock customer support

- Convenient online submission

- Thorough peer review

- Inclusion in PubMed and all major indexing services

- Maximum visibility for your research

Submit your manuscript at www.biomedcentral.com/submit
) Biomed Central 